\title{
DESENHO DE ARQUITETURA: ENTRE O DOCUMENTO E A OBRA DE ARTE
}

\author{
Rodrigo Queiroz
}

O projeto de Arquitetura, assim como seu meio de comunicação mais imediato, o desenho, permeiam grande parte do conteúdo da edição 34 da Revista Pós. O desenvolvimento de necessárias técnicas de conservação, associado ao crescente interesse por exposições de Arquitetura, conferem ao desenho arquitetônico a contraditória condição de obra de arte. Em alguns casos, o desenho parece guardar a integridade e a inteireza de um conceito cujo limite é, justamente, a realidade irreversível do canteiro de obras e de uma cadeia produtiva ainda reconhecida pela precariedade. Como resultado de uma paradoxal utopia romântica, o desenho se preserva no tempo, como a imagem de um futuro possível, seja como promessa, seja como registro de uma ideia posta à prova por sua versão construída.

A seção Depoimentos, da presente edição, apresenta um relato sobre estado atual das estratégias de catalogação, conservação e difusão do acervo composto de mais de 400 mil desenhos (entre originais e reproduções), sob a responsabilidade da Biblioteca da FAUUSP.

Organizado pelo professor titular Ricardo Marques de Azevedo (presidente do Conselho da Biblioteca da FAUUSP), pelas bibliotecárias Dina Elisabete Uliana e Eliana de Azevedo Marques, e pela pesquisadora Stella Regina Miguez, o $1^{\circ}$ Seminário Acervos de Arquitetura: Administração, Conservação e Difusão, ocorrido entre 15 e 17 de outubro de 2012, no auditório da FAUUSP, contou com a participação de diversos especialistas estrangeiros, entre eles, Albert Gumlich (conservador do Departamento de Conservação e Preservação do Getty Research Institut de Los Angeles) e Valentina Moimas (historiadora chefe do Departamento de Arquitetura e de Aquisições de Novas Coleções do Centro Georges Pompidou de Paris).

$O$ debate sobre modos eficientes de administração, conservação e difusão de acervos de Arquitetura vem ao encontro da urgente atualização das técnicas, dos equipamentos e, principalmente, dos espaços destinados à correta manipulação e depósito de um acervo de desenhos que cresce a passos largos, em decorrência do grande número de doações que a biblioteca da FAUUSP vem recebendo ultimamente, fator que exige a irreversível ampliação de seu espaço físico, dentro e, por que não, fora do Edifício Vilanova Artigas.

Soma-se à necessária revisão dos procedimentos de conservação dos desenhos, o crescimento do interesse por exposições de Arquitetura. Basta observarmos a gradual popularização de exposições dessa categoria, como Paulo Mendes da Rocha: Arquitetura e geografia natureza e construção (2011), Le Corbusier, América do Sul, 1929 (2012), e Gregori Warchavchik metrópole, Arquitetura (2013/2014), todas elas realizadas pelo Centro Universitário Maria Antonia (Ceuma) e com a participação efetiva de professores da FAUUSP, sendo, a última, composta quase que integralmente por documentos pertencentes ao acervo da Biblioteca da FAUUSP, com curadoria de José Tavares Correia de Lira. Soma-se às três, a mais recente edição da Bienal de Arquitetura de São Paulo, curada por Guilherme Wisnik e Ana Luiza Nobre, que ocupou diversas instituições culturais da cidade, como o Centro Cultural São Paulo, o Museu de Arte Assis Chateaubriand (Masp), o Sesc Pompeia, além do próprio Ceuma.

Com exceção das perspectivas, os desenhos de Arquitetura que integram o acervo da Biblioteca da FAUUSP, assim como os desenhos de Arquitetura de modo geral, lançam mão do código gráfico da geometria descritiva, procedimento que permite a elaboração e a posterior leitura de projetos, a partir de vistas em projeção ortogonal, que resultam em plantas, cortes e elevações. Como apoio a uma linguagem restrita ao metiê, essas exposições utilizam-se de outros meios de comunicação, como maquetes, fotografias e vídeos, para sua plena compreensão por parte de um público mais amplo.

Para além de mera construção, tais exposições revelam a Arquitetura como uma proposição 
intelectual, técnica e estética, fundamental para o entendimento de sua condição na sociedade atual.

Do mesmo modo que a Arquitetura ocupa, em crescimento exponencial, os espaços expositivos de museus e centro culturais, o inverso também revela sua importante função, como elemento de identificação que muitas vezes se confunde com a instituição que abriga, como podemos atestar nos projetos de Affonso Eduardo Reidy para o Museu de Arte Moderna do Rio de Janeiro (MAM-Rio), e de Lina Bo Bardi para o Masp, sendo que este último retém em si não apenas a imagem do museu, mas consiste em um componente devidamente incorporado ao imaginário da própria capital paulista.

A recente ampliação do Museu de Arte USP) fez que suas obras, de valor e importância inestimáveis, ultrapassassem os "longínquos" domínios além-rio do campus Butantã da USP e, desde janeiro de 2012, ocupassem o Palácio da Agricultura, edifício integrante do Parque Ibirapuera, local que abriga o maior conjunto arquitetônico moderno do Brasil, depois, claro, do Plano Piloto de Brasília. Agora, sob o teto de um edifício assinado por Oscar Niemeyer, não tardará a que esse museu universitário seja identificado pelos monumentais pilotis em "V" que caracterizam tal projeto. Assim como no MAM-Rio e no Masp, no caso do MAC-USP, devido a seu caráter arquitetônico e simbólico, o edifício assumirá um papel duplo, de abrigo e obra. Aliás, ante essa nova realidade, não seria sem propósito aventar a possibilidade de o MAC-USP receber os desenhos originais do conjunto do arquitetônico do Ibirapuera - que agora inclui o próprio museu -, como parte definitiva de seu acervo, e, quem sabe, figurar como o conjunto inaugural de uma possível coleção de Arquitetura, aos moldes do Museu de Arte Moderna de Nova York, ou do Centro Georges Pompidou em Paris.

Coincidentemente, mais da metade dos artigos que integram esta edição abordam, cada um à sua maneira, diferentes aspectos do projeto de Arquitetura. Vale lembrar que não cabe ao editor da Revista Pós escolher os artigos a serem publicados. Os artigos de cada edição são definidos pela ordem de chegada das aprovações de seus respectivos pareceristas. No que tange aos artigos científicos, é

responsabilidade do editor apenas a definição da sequência em que serão publicados.

Da aplicação didática de estratégias projetuais, à análise de autores ou obras específicas, este primeiro conjunto de artigos reflete sobre os procedimentos de projeto, ao apontar seus desdobramentos no ensino, na prática profissional e na própria história da Arquitetura. Segue uma breve apresentação dos artigos que integram esta edição.

Em "Comprometimento, motivação e processo criativo: um ponto de vista e sua aplicação na introdução ao projetar arquitetônico", Marise F. Machado apresenta sua experiência como docente da disciplina Concepção da Forma Arquitetônica 2, no curso de graduação em Arquitetura e Urbanismo da UFRJ. A disciplina consiste em um importante instrumento para o desenvolvimento de uma consciência crítica e estética, por parte dos alunos, antes mesmo do ingresso nas disciplinas de projeto de Arquitetura, cujos conteúdos e métodos ainda são reduzidos àqueles fatores tradicionalmente associados a condicionantes mais concretos, como programa, sistema estrutural, terreno, legislação etc., em detrimento de conteúdos mais abstratos, ligados à linguagem e seus desdobramentos, sendo estes abordados pela disciplina CFA2, ministrada pela autora.

O artigo "Expertise em projeto: como conhecimentos, experiências e habilidades diferenciam arquitetos expertos dos novatos", de Wilson Florio e Rafael Peres Mateus, assim como o anterior, aborda o processo de geração da forma arquitetônica, mas, neste caso, trata-se de uma avaliação da relação entre experiência e procedimento projetual. Os autores concluíram "que arquitetos expertos realizam projetos com maior desenvoltura que arquitetos novatos", a partir de uma experiência na qual três arquitetos experientes e três nem tanto foram convidados a projetar, em um condomínio residencial de alto padrão, na cidade de Santos, uma residência unifamiliar hipotética. Enquanto os seis arquitetos do grupo projetavam a casa, os autores verificaram seus diferentes percursos, das primeiras especulações ao desenvolvimento do estudo definitivo, e notaram que os arquitetos mais experientes permanecem por mais tempo na elaboração de esboços iniciais, e desenvolvem o projeto propriamente dito com mais 
rapidez. A proporção inversa, entre concepção e desenvolvimento, foi verificada no grupo de arquitetos com menos experiência.

Simone Neiva e Rafael Perrone, em "A forma e o programa dos grandes museus internacionais", abordam as transformações espaciais, formais e tipológicas da Arquitetura de museus, a partir da análise de projetos elaborados no século 20 , nem todos construídos, como o Museu do Crescimento llimitado (Le Corbusier, 1939) e o Museu para uma Pequena Cidade (Mies van der Rohe, 1942), de Mies van der Rohe. Apesar de a Arquitetura moderna ser notadamente reconhecida pela ruptura de uma estrutura tradicional, os autores demonstram que, em determinados projetos, como o Guggenheim de Nova York (Frank Lloyd Wright, 1943/1959), esse processo emancipatório é acompanhado do respeito por uma hierarquia espacial consagrada (a rotunda e a cúpula), mas que se formaliza a partir da incorporação de uma continuidade espacial tipicamente moderna.

Em "História de um lugar moderno: Clorindo Testa e o Centro Cívico de Santa Rosa, La Pampa", a autora, Cláudia Costa Cabral, faz uma análise do projeto do arquiteto Clorindo Testa, para o Centro Cívico da cidade argentina de La Pampa. Tributário das postulações modernas, o projeto de Testa consiste no enfrentamento do "vazio incomensurável que precede a civilização", que define a paisagem dos pampas. Não apenas como marco simbólico de uma afirmação moderna localizada no limite entre a cidade propriamente dita e a imensidão dos pampas, o presente artigo aborda o referido projeto a partir de seu aparentemente irreversível caráter inconcluso, e, a partir dessa condição, revela um traço inerente ao projeto do espaço moderno: uma inteligência que, por definição, é incapaz de definir seus próprios limites.

A continuidade que define a superfície moderna também é abordada no artigo "Sujeito sociológico pelas ruas de Brasília", de Roberta Tiburri. Definido por Stuart Hall, em seu livro "Identidade cultural na pós-modernidade", o isolamento e a autonomia que identificam esse "sujeito sociológico", segundo a autora, representam "a síntese para a qual Brasília foi projetada". E será a partir desse pressuposto que se estabelecerão interessantes relações entre a abstração do espaço moderno e o indivíduo, pretensamente formado a partir de um ethos que, acreditava-se, poderia emanar da própria experiência com aquele espaço projetado, em sua totalidade.

Em "This is paradise: I wish I had a lawnmower. A sociedade e paisagem motorizada nos Estados Unidos da América", José Luis Possolo de Saldanha estabelece relações entre o papel do automóvel como instrumento de liberdade individual, na sociedade norte-americana na segunda metade do século 20, e seus desdobramentos na literatura, no cinema e na música, a partir de um diálogo melancólico com a imensidão "urban-spraw" que caracteriza o território americano e seus personagens: o movimento ininterrupto do texto de Jack Kerouac; das paisagens suburbanas musicadas, ao ativismo em favor da bicicleta, por parte de David Byrne; o caráter mítico do automóvel, traço marcante nas músicas de Tom Waits; e o retrato de uma urbanidade isolada e pacata, nos filmes de David Lynch.

"O sentido social do arranjo e ambiência em Amanã", de Thatyana de Souza Marques do Nascimento, faz uma análise da comunidade Boa Esperança, localizada na Reserva de Desenvolvimento Sustentável Amanã, no Amazonas, com a intenção de compreender como o significado de "lar" ultrapassa os estritos limites físicos da Arquitetura, ao expandir-se para a escala da paisagem, mais precisamente o Lago Amanã, ambiente onde a sociabilização entre os moradores se estabelece.

Ainda sobre a Amazônia, em "Fotografia na Amazônia Brasileira: considerações sobre o pioneirismo de Christoph Albert Frisch (1840/1918)", o autor, José Leonardo Homem de Mello Gâmbera, discorre sobre o papel da fotografia documental, a partir da análise dos registros realizados pelo alemão Christoph Albert Frisch, em 1865, reconhecidos como as primeiras fotografias da Amazônia. Distante do olhar estrangeiro sobre a hostil paisagem intocada, as imagens capturadas por Frisch informam sobre o modo vida do homem na floresta, ao voltar seu olhar para as construções e os artefatos indígenas, e o transporte fluvial.

No artigo "As áreas verdes no contexto do Planejamento Urbano em São Paulo: os parques da gestão Setúbal (1976-1979)", a autora, Ana Cláudia Castilho Barone, discorre sobre as motivações e as 
circunstâncias que levaram o Prefeito Olavo Setúbal (1976/1979) a criar nove parques públicos na cidade de São Paulo, sendo, a maioria deles, localizada em zonas periféricas, como o Parque do Carmo, em São Mateus, e o Parque Anhanguera, em Perus. A carência de áreas verdes na cidade, associada à consciência ambiental que se inicia no período, parecem ser as balizas dessa revisão sobre a importância dos parques urbanos em São Paulo. João Mascarenhas Mateus, em "A Vila Matarazzo na Avenida Paulista e Tomaso Buzzi: projeto e obras (1938/1940)", apresenta um histórico do projeto e da execução da ampliação (1938/1940) da Vila Matarazzo (1896), de autoria do arquiteto Tomaso Buzzi, localizada na Avenida Paulista e recentemente demolida, para dar lugar a um centro e compras e serviços. Para além da publicação da iconografia gráfica e fotográfica da reforma, o artigo pretende posicionar Tomaso Buzzi como o devido autor do projeto, que, segundo Mateus, é erroneamente atribuído a outros dois arquitetos italianos, Marcello Piacentini e Vittorio Morpurgo. Encerrando a seção Artigos, em "Criando modelos tridimensionais para a inclusão de requisitos de acessibilidade em projetos arquitetônicos", os autores, Silvana da Rocha Rodrigues, Alexandre Sztajnberg, Rosa Maria E. M. Costa e William Seba Mallmann Bittar, apresentam meios para facilitar a compreensão, por parte do público leigo, da representação gráfica em projetos de acessibilidade, a partir da apresentação de um conjunto de ferramentas digitais integradas ao software SketchUp, largamente utilizado pelos profissionais da área.

Na seção Eventos, o professor do Departamento de Tecnologia da FAUUSP Artur Rozestraten faz um relato sobre o minicurso "Imaginário da Arquitetura", realizado na FAUUSP em outubro de 2013, com a participação de Jean-Jacques Wunenburger, professor da Faculdade de Filosofia da Universidade Jean Moulin, Lyon 3. Com o tema "O imaginário da Arquitetura para além dos arquitetos", um dos temas abordados pelo minicurso foram festividades típicas do interior do Brasil, como o Círio de Nazaré, e seus instigantes personagens, portadores de maquetes ricamente ornamentadas como parte de um figurino singular. No tema "Imagem e imaginário nas cidades", a cidade São Paulo, em pleno processo de verticalização, registrada pelas fotografias do acervo do escritório de Ramos de Azevedo (pertencente à Biblioteca da FAUUSP) foi objeto de discussão entre os participantes, assim como a própria estrutura e ensino da FAUUSP, debatidos no tema "Poéticas, rêveries e a formação técnico-científica contemporânea".

Nesta edição, todos os livros da seção Resenhas são de autoria de professores da FAUUSP. São eles: "São Paulo: um novo olhar sobre a História. A evolução do comércio de varejo e as transformações da vida urbana", de Beatriz Piccolotto Siqueira $(A \cup H)$, resenhado por Heloisa Barbuy; "Gustavo Giovannoni: textos escolhidos", organizado por Beatriz Mugayar Kühl (AUH), com resenha de Mirandulina Maria Moreira Azevedo; "Metrópoles e o desafio urbano frente ao meio ambiente", de Marcelo de Andrade Roméro (AUT) e Gilda Collet Bruna (AUP), com resenha de Vladimir Bartalini (AUP). Por fim, vale destaque a publicação “Design sem fronteiras: a relação entre o nomadismo e a sustentabilidade", de Lara Leite Barbosa (AUP), resenhada por Marcos Beccari, e que recebeu uma das mais importantes premiações do ramo editorial: o $3^{\circ}$ lugar do Prêmio Jabuti 2013, na categoria Arquitetura e Urbanismo.

Sabemos que não são poucos os desafios a serem enfrentados por uma publicação vinculada a um programa de pós-graduação específico, principalmente frente às exigências advindas de critérios quantitativos que, às vezes, ganham uma importância que torna qualquer discussão sobre conteúdo algo menor. Certamente, enfrentar e propor alternativas a um paradoxo aparentemente insolúvel é um dos objetivos desta revista. Por isso, aproveito o espaço deste editorial para cumprimentar a professora Mônica Junqueira de Camargo, que nos últimos quatro anos desenvolveu um trabalho exemplar como editora-chefe da Revista Pós. Neste próximo quadriênio, espero poder dar continuidade a seus esforços na difusão do conhecimento em Arquitetura e Urbanismo.

Boa leitura!

\section{Rodrigo Queiroz}

Editor-Chefe roqueiro@usp.br rvposfau@usp.br 